\title{
CASE OF REMARKABLE
}

\section{HYPERTROPHY OF THE FINGERS, \\ IN A GIRL,}

WITk A NOTICE OF SOME SIMILAR CASES.

BY T. B. CURLING,

LECTURER ON SURGERY, AND ASSISTANT-SURGEON AT THE LONDON

HOSPITAL, ETC.

Received January 14th-Read April 22nd, 1845.

THE subject of this excessive growth of some of the fingers of both hands, is Eliza Hitchcock, aged 15, an inhabitant of Bethnal Green; and I am indebted to Mr. Vandenburg, a medical practitioner in that district, for calling my attention to the case. She is a pale, sickly-looking girl, rather short for her age, the daughter of poor parents, and has to work for her subsistence. Her mother informs me that several of her daughter's fingers were remarkably large at birth. The following is an account of their present state, which is well represented in the drawings.* On the right hand, the fore, middle, and ring fingers are of unusual size. The relative enlargement of the fore and ring fingers is only slight, but the middle one is of extraordinary proportions. It measures as much as five inches and a half in length, and four in circumfer-

* See PI. II. and III.

VOL. XXVIII. 
ence at the first phalanx, and is in every respect properly formed. On the left hand, the thumb, index, and middle fingers are hypertrophied, the ring and little fingers remaining of the natural size, and presenting a curious appearance, in contrast with their gigantic neighbours. The finger most enlarged is the index, which measures five inches and a quarter in length, and four inches in circumiference. The thumb and middle finger are hypertrophied in a less degree. The middle finger has a lateral incurvation outwards, occasioned apparently by a displacement of the extensor tendon, which forms a bridle along its outer edge. The other enlarged fingers are of the normal shape.

All parts of these hypertrophied fingers are equally developed in excess-the bones, articulations, integuments, and nails. The middle finger of the right hand and index finger of the left, which have attained the greatest growth, are fixed in an extended position, the girl being unable to bend them. The motions, however, of the several articulations are not destroyed, but the fingers are stiff, probably from long continuance in the straight position; and the girl's inability to bend them appears to be owing to the flexor muscles in the fore-arm not having acquired a development corresponding to the fingers upon which they act, as the motions of those fingers which are hypertrophied in a less degree, are very little, if at all, impaired. The other parts of the upper extremities are in proper proportion to the size of the body. 
There is merely a fulness at those parts of the hands from which the hypertrophied fingers proceed. Indeed, with these exceptions, all the different parts of the body are of appropriate size and form. The fingers generally feel cold and numb, but their sensation is not impaired, and she is not subject to chilblains in them. Pulsation can be detected in the digital arteries, but it is indistinct, which is not surprising, as the girl is in weak health, and the circulation is feeble. She constantly uses her hands in household work, and also in needle work, at which she is tolerably skilful.

On comparing the hypertrophied fingers of this girl, with those of the famous giant $\mathrm{O}^{\prime}$ Byrne, whose skeleton, preserved in the Hunterian Museum, measures eight feet in height, I found that the two fingers in which the hypertrophy is most remarkable, are only half an inch shorter than the corresponding fingers of the giant.

I first saw this girl in the month of August 1839 , at which time some wax models of the hands were made, and placed in the London Hospital Museum. On now comparing the hands with these models, I find that the middle finger of the right hand, and the fore finger of the left, have each grown an inch in length since that period.

This case is a remarkable example of partial hypertrophy, and though facts of this nature do not offer much of interest to the practitioner, they are worthy of record, and of the attention of the physiologist, as throwing light on the laws which regu- 
late the development and formation of the body. There is, in this instance, an apparent absence of all those circumstances which seem favourable to excessive growth-a feeble constitution, sparing nutriment, no extraordinary exercise of the part, and no enlarged vessels or activity of circulation, and yet the hypertrophy so curiously confined to a few fingers is perfect in its kind: the common integuments, the nails, the bones and vessels, all have been uniformly and equally developed in excess. It would seem as if the formative powers which we see, in some few cases, exercised to excess in every part of the frame, so as to make a giant, had been limited in this instance to an insignificant part of the extremities.

My friend, Professor Owen has favoured me with the following communication :-

“ College of Surgeons, January 6th, 1845.

"Having gone from the York Meeting last autumn, to the coal districts of Durham, in order to inspect the dwellings of the pitmen, I there saw a case of congenital hypertrophy of the fingers, analogous to the one of which you have shown me a drawing: the subject was a child, two years old, which the mother, wife of one of the pitmen of the great South Hetton Colliery, was nursing. Both hands were bandaged up, and she begged me to look at them : the middle finger of each, was nearly twice as long, and more than twice as thick, as the index finger, and the extremity of each was ulcerated, and additionally swollen by the inflammation; 
but the mother assured me that the child was born with those fingers as much bigger than the others, as they were when I saw them, except that then they were sound, and that they had swollen at the ends since they became sore. It appears, therefore, that they had preserved their relatively disproportionate size since birth, by normal growth, with an additional and more recent increase, through the stimulus of inflammation.

"I noted the case at the time, merely as one of congenital excess of development, and, being fully occupied by other inquiries, sought for no further particulars."

I am indebted to Mr. Paget, of St. Bartholomew's Hospital, for the following particulars of a malformed hand, a cast of which was given to me by $\mathrm{Mr}$. Dimond, of Frith Street, Soho Square. "It presents congenital hypertrophy of the first and second fingers of the right hand-the second is of enormous size. The cast is from a Spaniard, the Governor of the Fort at Luzon, one of thePhilippine Islands. In 1837, when it was taken, he was about 50 years of age, and a well-made man in every part except his hand. At birth, the large fingers bore the same proportions as when the cast was made; but their extraordinary size produced no inconvenience : he could write very well, and he used his hand as if there were nothing unusual about it. To avoid observation, he had the habit of carrying his hand within the breast of his coat; but except from the curiosity it excited, he suffered no discomfort from it." On ex- 
amining the cast, I particularly noticed that the middle finger, which was so largely hypertrophied, had the same kind of lateral incurvation outwards as was observed in one of the fingers of Eliza Hitchcock, so as completely to cross behind the adjoining fingers.

In the Museum of King's College, London, there is a cast of the left hand of an adult, in which the middle finger is hypertrophied, the others remaining of the natural size. The enlargement is uniform, and attended with a slight lateral inclination. The case is congenital, and the hands of other members of the family are reported to have been deformed in a similar manner.

This congenital form of hypertrophy is undoubtedly of rare occurrence, and there are very few cases of it on record. Mr. Power, of Dublin, has related an example which he met with in a girl five years old. He states, " the middle finger of her right hand is enlarged to the size it would naturally present in a very full grown, corpulent person : the metacarpal bone, and the phalanges, partake of this increased development, but are perfectly symmetrical. The thumb and the little finger are of the ordinary size, suitable to the age of the child, but the index and ring fingers are rather large, particularly the latter, and are divaricated from the middle, in consequence of its abnormal growth. On turning up the palm of the hand, the enlargement at the base of the phalanx of the hypertrophied finger is very remarkable, and gives this part of the hand the 
appearance of that of a grown person. The integuments are natural, and her left hand, figure, and lower limbs are perfect and symmetrical."*

Dr. John Reid has published the particulars of a case of increased nutrition in the thumb and first finger of the left hand. The first exceeded the middle finger in length, by about half an inch, and had twice the circumference. The thumb of the same hand was about a quarter of an incb larger than that of the right, and had nearly double the bulk. The radial artery of the left, seemed to be double the size of that of the right arm. The temperature of the enlarged fingers was higher by a few degrees than those of the other hand. The difference in size existed at birth, and continued to increase till the boy's death, which happened when he was 13 years of age. $\dagger$

In four of the foregoing cases, the hypertrophied fingers were bent to one side, and I suspect that in all of them this inclination was produced, as in the case of Eliza Hitchcock, by the tension of the displaced extensor tendon, which had not elongated in proportion to the increase in the size of the finger.

The deformity in these cases was of so offensive a character, that it is a point of some interest to determine whether it be possible by any mode of treatment to arrest the inordinate growth of the fingers in early life. It is questionable if this could be ac-

* Dublin Journ. of Med. Science, vol. xvii., p. 244.

$\dagger$ Lond. and Edin. Monthly Journ. of Med. Science, vol. for 1843, p. 198. 
complished by any other means than by firm and long-continued pressure, the effect of which in preventing growth is well displayed in the atrophied feet and toes of the Chinese ladies. But in addition to the suffering to which this plan of treatment gives rise, the impairment of the functions of the part, caused by long-continued pressure, constitutes an insuperable objection to its employment. In a case where one finger only was enlarged to a great extent, and at the same time nearly useless, and interfering with the motions of the adjoining fingers, as was apparently the case with the Spanish Governor, the hypertrophied finger might be removed by operation. In other cases, the enlarged finger might be reduced to a more moderate size by amputation of the distal phalanx; and in this reduced state, the muscles would probably recover their power over it.

Excessive growth has been observed even less frequently in the toes than in the fingers. My colleague at the London Hospital, Dr. Little, lately showed me a cast of the foot of a child, in which the second and third toes were hypertrophied to double their natural size, and also united by the common integuments. Dr. Reid mentions an instance of increased nutrition in one toe of a female child aged two years. The middle toe of the left foot projected about three fourths of an inch beyond the great toe, and taking its breadth along with its length, it equalled in bulk all the remaining four toes.*

$$
\text { * Lib. cit. }
$$




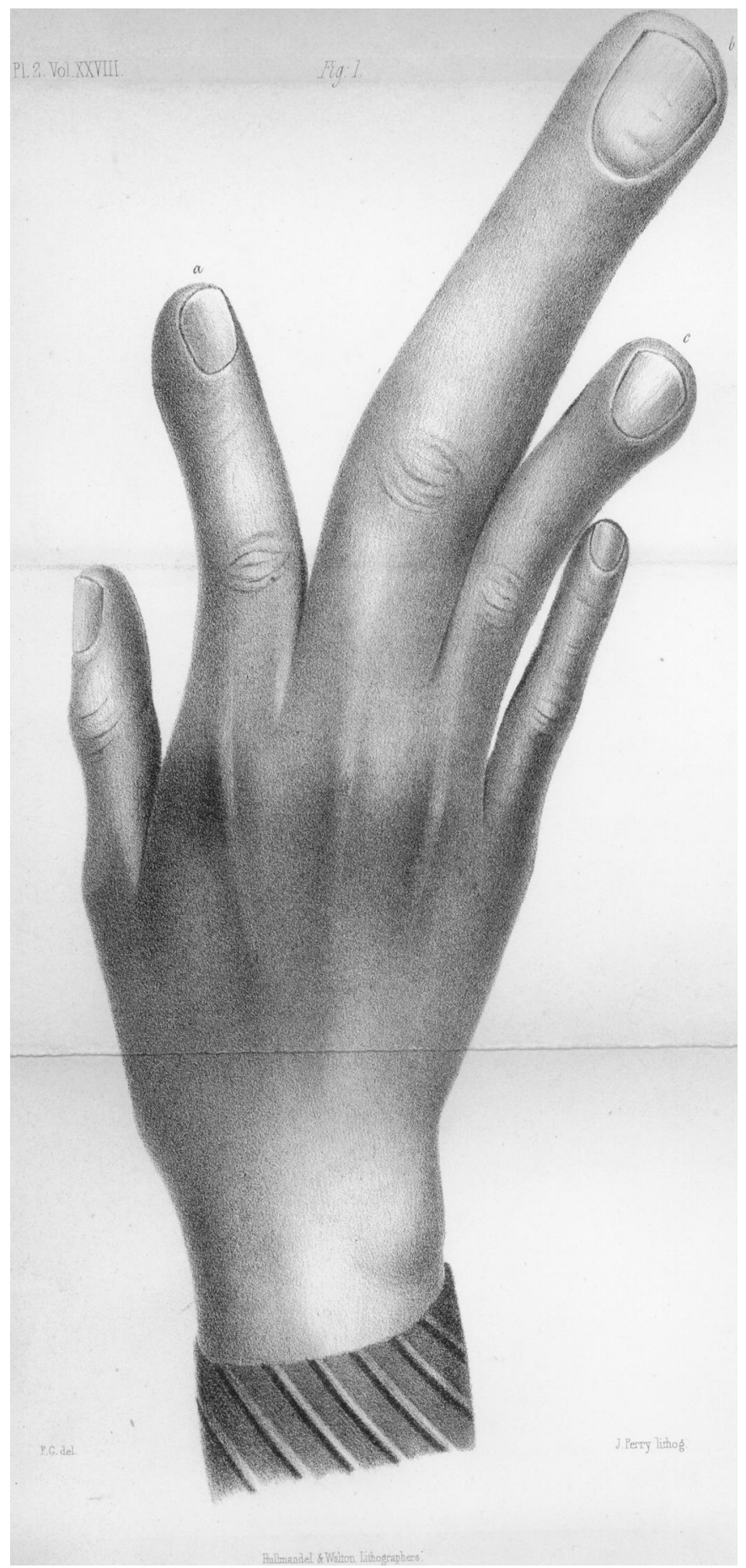

